www.nature.com/ejhg

\title{
Demographics of the UK cystic fibrosis population: implications for neonatal screening
}

\author{
Jonathan McCormick ${ }^{*, 1}$, Michael W Green ${ }^{1}$, Gita Mehta ${ }^{1}$, Frank Culross ${ }^{1}$ and Anil Mehta ${ }^{1}$ \\ ${ }^{1}$ The UK CF Database, Tayside Institute of Child Health, Ninewells Hospital, Dundee DD1 9SY, UK
}

The objective was to determine the composition of the Cystic Fibrosis (CF) Population attending specialist UK CF centres in terms of age, gender, age at diagnosis, genotype and ethnicity. With the planned introduction of the national CF screening programme in the UK, cystic fibrosis transmembrane regulator (CFTR) mutations were compared between different ethnic groups enabling a UK-specific frequency of mutations to be defined. Data were analysed from the patient biographies held in the UK CF Database (see www.cystic-fibrosis.org.uk). The currently registered population of 5274 CF patients is 96.3\% Caucasian with a male preponderance that significantly increases with age. The majority of the 196 non-Caucasian CF patients are from the Indian Subcontinent (ISC), of which one in 84 UK CF patients are of Pakistani origin. The commonest CFTR mutation, $\triangle F 508$, is found in $74.1 \%$ of all CF chromosomes. In the Caucasian CF population, $57.5 \%$ are $\triangle F 508$ homozygotes but the UK ISC CF population with only $24.7 \%$, has significantly fewer $\Delta \mathrm{F} 508$ homozygotes patients $(95 \%$ confidence interval $(\mathrm{Cl}) 0.2-0.4)$. The distribution of Caucasian patients with $\Delta \mathrm{F} 508 / \Delta \mathrm{F} 508, \Delta \mathrm{F} 508 /$ Other and Other/Other does not fit the expected distribution with a Hardy-Weinberg model unless those patients without a detected mutation are excluded $(P<0.001)$. The UK CF Database has shown the UK CF population to have distinct characteristics separate from the North American and European CF Registries. The ISC group contains many mutations not recognised by current genetic analysis, and one in four ISC patients have no CFTR mutations identified. The CFTR analysis proposed for the screening programme would detect $96 \%$ of patients registered in the database, but is unlikely to achieve the desired $>80 \%$ detection rates in the ethnic minority groups. Screen-positive, non-Caucasian infants without an identifiable CFTR mutation should be referred for a sweat test and genetic counselling when serum trypsinogen concentrations remain elevated after birth.

European Journal of Human Genetics (2002) 10, 583-590. doi:10.1038/sj.ejhg.5200850

Keywords: cystic fibrosis; epidemiology; ethnicity; race; CFTR; mutation

\section{Introduction}

Cystic Fibrosis (CF) remains the commonest life-limiting autosomal recessive condition to affect the Caucasian UK population with a median age of death in the second decade for those born in the 1980s. There have been around 1000 individual CFTR mutations categorised since the landmark identification of the CFTR gene in $1989 .{ }^{1}$

\footnotetext{
*Correspondence: J McCormick, The UK CF Database, Tayside Institute of Child Health, Ninewells Hospital, Dundee DD1 9SY, UK.

Tel: 44 1382 632179; Fax: 44 1382 632597;

E-mail: jdmccormick@btinternet.com;

Web site: www.cystic-fibrosis.org.uk

Received 3 April 2002; revised 23 May 2002; accepted 6 June 2002
}

The application of new anti-microbial therapies and nutritional knowledge have seen the outlook for CF patients born today improve such that survival into the fourth and fifth decades is possible with specialist care. It is presently unknown whether survival will improve further with the introduction of neonatal screening for cystic fibrosis in Scotland in 2002/3, because the impact of the CFTR mutation on the subsequent pattern and severity of symptoms experienced by the patient remains controversial. With respect to neonatal screening, Farrell's Wisconsin cohort has shown some patient benefits of screening through long-term surveillance ${ }^{2}$ but the controversy will only be settled by long-term analysis of trends using CF 
Table 1 Mode of presentation of the UK CF patients

\begin{tabular}{llll}
\hline Mode of presentation & $\begin{array}{l}\text { Percentage of total } \\
\text { patient population } \\
(\%)(\mathrm{n}=5274)\end{array}$ & $\begin{array}{l}\text { Percentage of caucasian } \\
\text { patient population } \\
(\%)(\mathrm{n}=5078)\end{array}$ & $\begin{array}{l}\text { Percentage of ISC } \\
\text { patient population } \\
(\%)(\mathrm{n}=88)\end{array}$ \\
\hline Failure to thrive/malnutrition & 35.8 & 35.4 & 38.6 \\
Lower respiratory tract infection & 34.6 & 34.4 & 39.8 \\
Steatorhoea & 29.0 & 28.9 & 28.4 \\
Meconium ileus+/-distal intestinal obstruction syndrome & 13.2 & 13.2 & 14.8 \\
Screening & 11.7 & 11.7 & 4.5 \\
Family history & 11.1 & 11.3 & 12.5 \\
Other reason & 4.4 & 4.4 & 3.4 \\
Rectal prolapse & 3.7 & 3.7 & 1.1 \\
Unknown reason & 2.7 & 2.8 & 2.3 \\
Electrolyte imbalance & 1.6 & 1.5 & 0 \\
Sinus disease/polyps & 0.7 & 0.6 & 1.1 \\
Prolonged jaundice & 0.5 & 0.5 & 0 \\
Infertility & 0.5 & 0.5 & 0 \\
\hline
\end{tabular}

Table 2 Age at diagnosis of the UK CF patients

\begin{tabular}{llll}
\hline $\begin{array}{l}\text { Age at } \\
\text { diagnosis } \\
\text { (years) }\end{array}$ & $\begin{array}{l}\text { Percentage of UK } \\
\text { CF population } \\
(\%)(\mathrm{n}=5274)\end{array}$ & $\begin{array}{l}\text { Percentage of } \\
\text { Caucasian UK CF } \\
\text { population }(\%)(\mathrm{n}=5078)\end{array}$ & $\begin{array}{l}\text { Percentage of UK } \\
\text { CF patients from } \\
\text { the ISC }(\%) \\
(\mathrm{n}=88)\end{array}$ \\
\hline $0-<1$ & 63.1 & 63.0 & 71.6 \\
$1-<4$ & 23.5 & 21.7 & 15.9 \\
$4-<7$ & 5.6 & 5.8 & 3.4 \\
$7-<10$ & 2.1 & 2.0 & 1.1 \\
$10-<40$ & 5.4 & 5.4 & 8.0 \\
$40-<70$ & 0.2 & 0.3 & 0.0 \\
Unknown & 1.8 & 1.9 & 0.0 \\
\hline
\end{tabular}

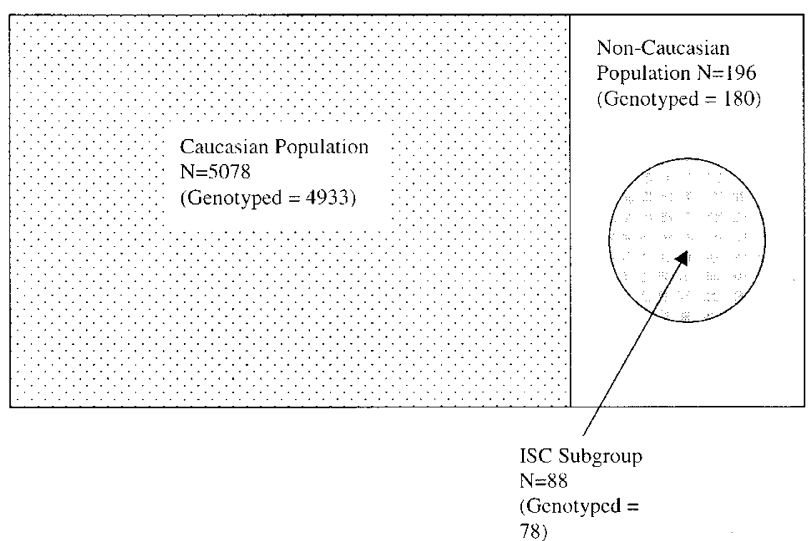

Figure 1 UK CF population subgroups. The registered UK population divided into the Caucasian and non-Caucasian Groups, including those patients who have been genotyped. The ISC Group are shown as a subgroup within the non-Caucasian Group, although the diagram is not to scale.

Registries. The UK CF Database contains such a registry within one of its modules and aims to analyse the clinical details of every cystic fibrosis patient in the United King- dom who attends a specialist CF centre. This article presents the demographics of the currently registered UK CF population focusing on the gender, ethnicity, mode of presentation and genotypes of the 5274 patients from an estimated UK population of approximately 7500 patients. ${ }^{3}$ The considerable impact of ethnicity on CFTR mutations in the UK is shown.

\section{Methods}

The UK CF Database was established at the Tayside Institute of Child Health, University of Dundee, Scotland in 1995. The patient's age, gender, parental ethnicity, genotype, and method of diagnosis were included in the Patient Biographies and entered into the database from 56 paediatric and adult CF clinics, and validated through the system of double data entry, range checking and error correction. Full details of all procedures are available at www.cysticfibrosis.org.uk. We divided the UK CF population into two groups (Figure 1): the Caucasian Group and the non-Caucasian Group. Within the non-Caucasian Group, we created a subgroup called the ISC Group consisting of all Pakistani, Indian, Bangladeshi and Asian Other patients.

Data was analysed using Microsoft Access 97 software and included all patients registered by May 2001. Statistical 
Age and gender profile of UK CF patients (May 2001)

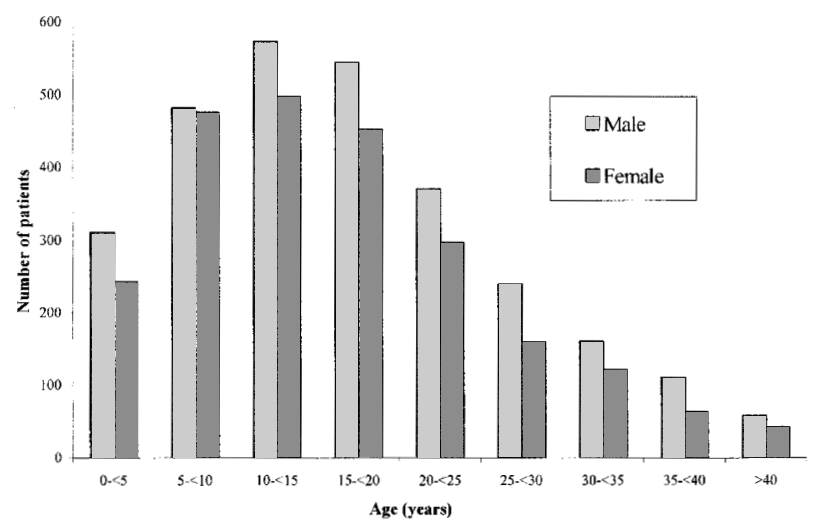

Sex Ratio with Age

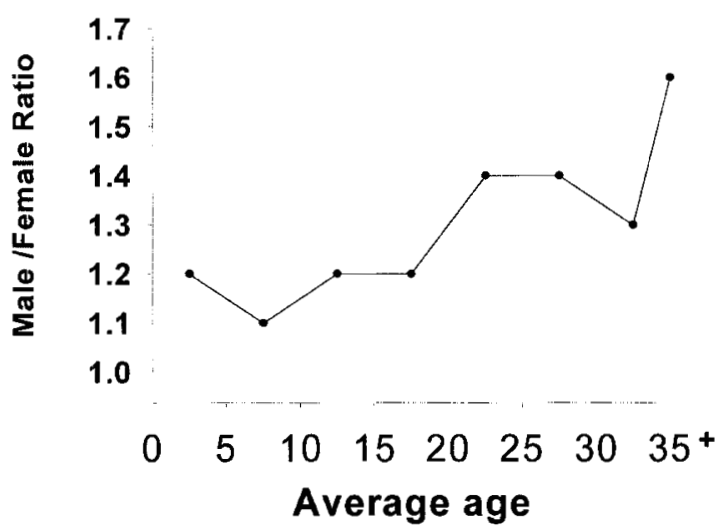

Figure 2 (a) Age and gender profile of UK CF patients; (b) Sex ratio by age. (a) The reduced number of patients in the $0-<5$ age group occurs because not all of them have presented. (b) Exhibits the increasing male/female ratio with age.

analysis is shown with $95 \%$ confidence intervals for the difference between two population proportions.

\section{Results}

There were a total of 5274 patients entered into the UK CF database. The gender split in the UK CF population is 2881 male (54.6\%) and 2393 female (45.4\%) with a male/female ratio that increases with age (Figure 2a,b). It can be seen that $49.1 \%$ of the entire population is under 15 years of age, $40.0 \%$ lies between 15 and 30 years, and only $11.0 \%$ of the population are still alive over the age of 30 years. There were 5078 patients in the Caucasian Group (96.3\%) and 196 in the non-Caucasian Group. This second group contains a subset of 88 patients forming the ISC group (63 Pakistani, 12 Indian, seven Bangladeshi and six Asian Other patients), the remainder comprising six Black Caribbean, three Black African and 99 others of mixed parentage. Therefore, one in every 27 UK CF patients has some non-Caucasian origin, with those of purely Pakistani origin accounting for one in $84 \mathrm{UK}$ CF patients.

The main presenting features that lead a clinician to consider a diagnosis of cystic fibrosis are failure to thrive, lower respiratory tract infections, steatorrhoea, meconium ileus, distal intestinal obstruction syndrome, family history, rectal prolapse, the presence of nasal polyps, electrolyte imbalance, prolonged jaundice or infertility (Table 1). The Caucasian and ISC subgroups both demonstrated similar patterns of presentation. Neonatal screening accounted for $11.7 \%$ of all diagnoses.

The median age of diagnosis was 4 months (range 0 months to 61 years 8 months). A diagnosis of CF occurred in $86.7 \%$ of all patients before their fourth birthday, and $63.1 \%$ were diagnosed before their first birthday. Diagnosis of cystic fibrosis beyond the age of 10 years was seen in $5.7 \%$ of all patients. To assess whether ethnic origin had any effect on age at presentation, Caucasian and ISC patterns of presentation were compared (Table 2). For Caucasian CF patients $(n=5078), 63.0 \%$ were diagnosed before their first birthday, $84.7 \%$ before their fourth birthday, and $5.6 \%$ beyond their 10 th birthday. In the ISC subgroup ( $n=88$ ), $71.6 \%$ of patients were diagnosed before their first birthday, $87.5 \%$ before their fourth birthday and $8.0 \%$ were diagnosed over the age of 10 . There was no significant difference in the proportions of those diagnosed before 1 year of age in the Caucasian and ISC populations (95\% Confidence Limits -0.02 and +0.19 ). UK CF patients of Black African or Black Caribbean origins ( $n=9)$ had a diagnosis rate of $77.8 \%$ before the age of four, and $22.2 \%$ over the age of 10 , but the numbers were too small to undertake statistical analysis.

Genotype data was available on 4933 patients that permitted further comparison of Caucasian and ISC patients to test the hypothesis that the genotypes were similar (Table 3). Patients with two chromosomes containing the $\Delta \mathrm{F} 508$ mutation account for $57.5 \%$ of the genotyped UK CF Caucasian population $(n=4753)$ but only $24.7 \%$ of the genotyped UK ISC CF patients ( $n=78)(95 \%$ CI $0.2-0.4$ in the difference between the proportions). In contrast, there are no F508 homozygotes in the Black African or Black Caribbean groups. Further differences are revealed in the ISC group with $4.7 \%$ showing $\Delta \mathrm{F} 508$ heterozygous status where the other CFTR mutation is either a known disease-associated allele or as yet uncharacterised. Importantly, patients with two known CFTR mutations, neither of which are $\Delta$ F508 make up $35.3 \%$ in the ISC population, many of these being family specific mutations. Thus at $27.1 \%$ of the ISC patients, a much larger proportion has no identifiable CFTR mutation compared to the Caucasian patient population.

The Caucasian population contains 4753 patients who have had their genotype tested (319 patients have not been tested, and six refused). The proportions of Caucasian 
Table 3 Genotypes of the UK CF Caucasian and ISC populations

\begin{tabular}{lll}
\hline & $\begin{array}{l}\text { Percentage of } \\
\text { genotyped UK CF } \\
\text { Caucasian population } \\
\mathrm{n}=4753(\%)\end{array}$ & $\begin{array}{l}\text { Percentage of } \\
\text { genotyped UK CF } \\
\text { ISC population } \\
\mathrm{n}=78(\%)\end{array}$ \\
Genotype & 57.5 & 24.7 \\
\hline$\Delta \mathrm{F} 508 / \Delta \mathrm{F} 508$ & 11.5 & 3.5 \\
$\Delta \mathrm{F} 508 /$ Unknown & 5.1 & 0.0 \\
$\Delta \mathrm{F} 508 / \mathrm{G} 551 \mathrm{D}$ & 2.8 & 0.0 \\
$\Delta \mathrm{F} 508 / \mathrm{G} 542 \mathrm{X}$ & 2.7 & 27.1 \\
Unknown/Unknown & 2.0 & 1.2 \\
$\Delta \mathrm{F} 508 / 621+1 \mathrm{G} \rightarrow \mathrm{T}$ & 2.0 & 0.0 \\
$\Delta \mathrm{F} 508 / \mathrm{R} 117 \mathrm{H}$ & 1.0 & 0.0 \\
$\Delta \mathrm{F} 508 / 1898+1 \mathrm{G} \rightarrow \mathrm{A}$ & 0.0 \\
$\Delta \mathrm{F} 508 / 1717-\mathrm{G} \rightarrow \mathrm{A}$ & 0.9 & 0.0 \\
$\Delta \mathrm{F} 508 / \mathrm{N} 1303 \mathrm{~K}$ & 0.8 & 0.0 \\
$\Delta \mathrm{F} 508 \Delta \mathrm{I507}$ & 0.8 & 0.0 \\
$\Delta \mathrm{F} 508 / \mathrm{R} 553 \mathrm{X}$ & 0.6 & 0.0 \\
$\Delta \mathrm{F} 508 / \mathrm{R} 560 \mathrm{~T}$ & 0.6 & 0.0 \\
$\Delta \mathrm{F} 508 / \mathrm{Q} 493 \mathrm{X}$ & 0.5 & 0.0 \\
G551D/Unknown & 0.4 & $15.3^{*}$ \\
Other/Other & 2.8 & 0.0 \\
$\Delta \mathrm{F} 508 /$ Other & 6.7 & 8.2 \\
Y569D/Y569D & 0.0 & 3.5 \\
L218X/L218X & 0.0 & 3.5 \\
1161delC/1161delC & 0.0 & 2.4 \\
R709X/V456A & 0.0 & 2.4 \\
G542X/G542X & 0.4 & 3.5 \\
Other/Unknown & 1.0 &
\end{tabular}

The shaded areas represent the commonest genotypes in the ISC population. *Includes 1525-1G $\rightarrow \mathrm{T} / 1525-1 \mathrm{G} \rightarrow \mathrm{T}, \quad \mathrm{Y} 569 \mathrm{C} / \mathrm{Y} 569 \mathrm{D}$, G551D/G551D, 1525-1G $\rightarrow$ A/1525-1G $\rightarrow$ A, R1162X/R1162X, R01/ 07/R01/07, 2184insA/2184insA, Y568D/Y568D, 1VSB1-1/1VSB1-1, $1506 \mathrm{M} / 1506 \mathrm{M}, \quad 3849+10 \mathrm{kbC} \rightarrow \mathrm{T} / 3849+10 \mathrm{kbC} \rightarrow \mathrm{T}$ and Q98X/ Q98X.

patients with $\Delta \mathrm{F} 508 / \Delta \mathrm{F} 508, \Delta \mathrm{F} 508 /$ Other and Other/Other (where Other is either a known or an unknown non$\Delta$ F508 mutation) were compared with expected values to see if the distribution fitted a Hardy-Weinberg model. From our data the maximum likelihood estimate of $P$ is 0.751 (the proportion of $\Delta$ F508 in the population). Using our estimate of $P$ to fit a Hardy-Weinberg model, we find that the observed number of $\Delta \mathrm{F} 508 / \Delta \mathrm{F} 508$ and Other/ Other is greater than expected. Wahlund's effect (http:// darwin . eeb . uconn . edu / eeb348 / lecture - notes / wahlund / wahlund.html) may partly explain the excess of $\Delta \mathrm{F} 508 /$ $\Delta \mathrm{F} 508$, but this influence would also affect the other groups. However, when we exclude those patients without easily detectable CFTR mutations $(n=124)$, the data satisfies Hardy-Weinberg equilibrium using a $\chi^{2}$ goodness-of-fit test (Observed: Expected $\Delta$ F508/ $\Delta$ F508 2734:2755, $\Delta$ F508/Other $1674: 1632$ and Other/Other $221: 242$ ).

A total of 4933 patients have had their genotype tested, and Table 4 shows the gene frequency of different CFTR mutations amongst these 9866 chromosomes. We conducted a virtual study noting that the proposed Scottish screening programme includes a panel of 31 CFTR mutations (David Aitken, Guthrie Institute, Glasgow personal communication). These 31 mutations were compared with a 'virtual DNA kit' constructed from the 27 mutations shown in Table 4, composed of the 20 commonest mutations in the Caucasian Group and seven of the commonest mutations in the non-Caucasian Group. Amongst the different ethnic groups, Table 5 shows a comparison between the detection rates of at least one CFTR mutation using the 27-kit, the 31-kit and a virtual amalgam of 38 mutations (the 31-kit plus the additional seven non-Caucasian mutations used in the 27 kit). Overall, all the kits will detect $96 \%$ of all patients with at least one CFTR mutation, and $97 \%$ of pure Caucasians. Only those of purely Indian origin approach the $>80 \%$ ideal threshold for a screening programme (detection rate 75\%). Irrespective of the kit used, a detection rate of $>87 \%$ will always occur in the mixed group and the screening programme will prove increasingly successful as the offspring of mixed relationships increase. Our data also shows that the 38mutation kit performs no better than our proposed 27 kit for ethnic minorities. Irrespective of the final decision on the UK panel of mutations to be included, the index of clinical suspicion should remain high in the ISC, Black African or Black Caribbean patients who have no Caucasian parentage. Achieving a $>80 \%$ detection rate for the UK patients in these ethnic groups is unlikely to be economically feasible due to the many individual/family specific mutations that would need to be included.

The regional distribution of $\mathrm{CF}$ patients, divided into three categories $(\Delta \mathrm{F} 508 / \Delta \mathrm{F} 508, \Delta \mathrm{F} 508 /$ Other and Other/ Other) is shown in Table 6 . The much greater proportion of Other/Other CF patients in Northern Ireland (and the corresponding drop in $\Delta \mathrm{F} 508 / \Delta \mathrm{F} 508)$ was statistically significant compared to every other region in the UK $(P<0.05)$.

\section{Discussion}

The UK CF database has registered 5274 patients and characterises the majority of the CF specialist clinic population for the start of the new millennium. We have shown that the non-Caucasian CF population makes up 3.6\% of the UK CF population and their range of CFTR mutations are markedly different to the Caucasian patients although they were diagnosed at similar ages and with similar symptoms.

\section{Screening in the UK}

Some of the best evidence for supporting a neonatal screening programme is based on Farrell's evidence for nutritional benefits. $^{2}$ The Cochrane review ${ }^{4}$ found a second randomised controlled trial from the $\mathrm{UK}^{5}$ that did not show a benefit to early diagnosis but is of interest that in the latter study, patients screened for CF were not all referred to a specialist centre for their care. Thus the criterion that appropriate treatment facilities should be in place postscreening was not met in this study.

Screening in Scotland is scheduled to commence in $2002 / 3$. It is envisaged that the proposed screening programme will be based on a three-stage protocol. ${ }^{6}$ In 
Table 4 The commonest CFTR mutations in the UK

\begin{tabular}{|c|c|c|c|}
\hline CFTR mutation & $\begin{array}{l}\text { Genotypes UK CF population } \\
\text { ( } \mathrm{n}=9866 \text { chromosomes) } \\
\text { gene frequency per } 1000 \text { genes }\end{array}$ & $\begin{array}{l}\text { Genotyped UK Caucasian CF } \\
\text { population ( } \mathrm{n}=9506 \text { chromosomes) } \\
\text { gene frequency per } 1000 \text { genes }\end{array}$ & $\begin{array}{l}\text { Genotyped UK CF ISC } \\
\text { population ( } \mathrm{n}=156 \text { chromosomes) } \\
\text { gene frequency per } 1000 \text { genes }\end{array}$ \\
\hline$\Delta \mathrm{F} 508$ & 741.0 & 752.0 & 294.9 \\
\hline G542X & 18.5 & 18.4 & 25.6 \\
\hline $\mathrm{R} 117 \mathrm{H}$ & 12.5 & 12.7 & 0.0 \\
\hline $621+1 \mathrm{G} \rightarrow \mathrm{T}$ & 12.7 & 12.7 & 6.4 \\
\hline N1303K & 5.6 & 5.4 & 0.0 \\
\hline$\Delta \mathrm{l} 507$ & 4.8 & 5.0 & 0.0 \\
\hline R560T & 4.2 & 4.3 & 0.0 \\
\hline R553X & 3.3 & 3.4 & 0.0 \\
\hline 1154insTC & 3.2 & 3.3 & 0.0 \\
\hline Q493X & 2.8 & 2.9 & 0.0 \\
\hline 3659delC & 2.8 & 2.9 & 0.0 \\
\hline 1078delT & 1.3 & 1.4 & 0.0 \\
\hline Y569D & 1.5 & 0.0 & 96.2 \\
\hline L218X & 0.6 & 0.0 & 38.5 \\
\hline $1161 \mathrm{delC}$ & 0.7 & 0.1 & 38.5 \\
\hline R1162X & 0.9 & 0.6 & 19.2 \\
\hline R709X & 0.4 & 0.2 & 12.8 \\
\hline $3849+10 \mathrm{kbC} \rightarrow \mathrm{T}$ & 1.2 & 0.8 & 19.2 \\
\hline S549R* & 0.6 & 0.0 & 0.0 \\
\hline
\end{tabular}

${ }^{*}$ S549R mutations appear in the non-Caucasian but not the ISC subgroup.

Table 5 CFTR detection rates in different ethnic groups

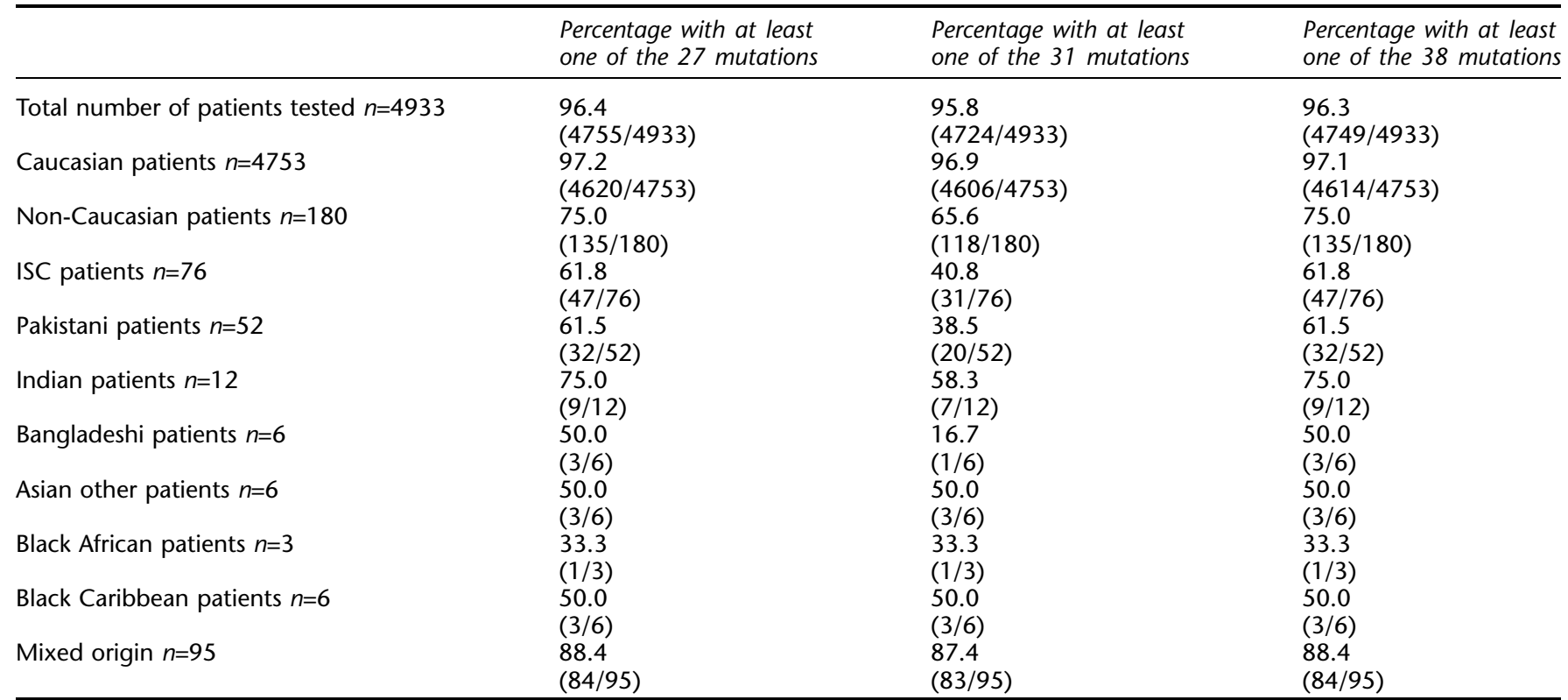

Only those patients who have had genotype analysis are included; 335 patients had not had their genotype tested and six patients refused genotyping. Twenty of the CFTR mutations in the 31 panel also appear in the 27 mutations listed in Table 4 . The additional eleven are $\mathrm{S} 549 \mathrm{~N}$, $3849+4 \mathrm{~A} \rightarrow \mathrm{G}, 3905$ ins T, 2789+5G $\rightarrow \mathrm{A}, \mathrm{Y} 122 \mathrm{X}, 711+1 \mathrm{G} \rightarrow \mathrm{T}$, R347P, R347H, R334W, A455E and 3281AA $\rightarrow$ G. The following seven mutations appear in Table 4 but not in the 31 mutation panel; 1154insTC, E60X, P67L, Y569D, L218X, 1161delC and R709X. 
Table 6 Regional distribution of genotypes: percentage of each region's CF population

\begin{tabular}{|c|c|c|c|c|c|}
\hline & $\begin{array}{l}\text { Scotland } \\
\mathrm{n}=697\end{array}$ & $\begin{array}{l}\text { Northern } \\
\text { Ireland } \\
\mathrm{n}=320\end{array}$ & $\begin{array}{l}\text { Wales } \\
\mathrm{n}=143\end{array}$ & $\begin{array}{l}\text { Northern } \\
\text { England } \\
\mathrm{n}=1411\end{array}$ & $\begin{array}{l}\text { Southern } \\
\text { England } \\
\mathrm{n}=2366\end{array}$ \\
\hline$\Delta \mathrm{F} 50$ & $51.9 \%$ & $39.4 \%$ & $45.5 \%$ & $51.4 \%$ & $63.9 \%$ \\
\hline$\Delta \mathrm{F} 508 /$ Other $^{* *}$ & $40.3 \%$ & $38.1 \%$ & $44.8 \%$ & $41.0 \%$ & $29.1 \%$ \\
\hline Other/Other** & $7.7 \%$ & $22.5 \%$ & $9.8 \%$ & $7.7 \%$ & $6.9 \%$ \\
\hline
\end{tabular}

**=Non- $\Delta$ F508 CF causing mutations.

the first stage, a confirmed raised immunoreactive trypsinogen (IRT) level on a day 4-6 blood spot sample would be followed by a second stage DNA analysis for CFTR mutations from the same blood spot card. Individuals with two CFTR mutations will be referred with a definite diagnosis of CF. Infants with only one CFTR mutation, or those with a very high IRT and of non-Caucasian origin who have no identified CFTR mutation, would undergo a third stage repeat blood spot for IRT on day 27 of life. If the latter IRT is also raised, the infant has a high probability of CF and will be referred for sweat testing and genetic counselling. If not, the infant has a low probability of CF and the family will be offered genetic counselling alone. With current knowledge, CFTR mutation analysis cannot provide the full answer for all, but selective application of an IRT IRT strategy is the only way of providing reasonable sensitivity, especially when screening non-Caucasian babies.

\section{CFTR mutations in Caucasians}

Large-scale CF studies have revealed common genotypes more prevalent in certain populations. Schwarz et al studied the distribution and frequency of Caucasian UK CFTR mutations in $1995^{7}$ and listed 20 of the commonest mutations. Nineteen of these mutations feature in the commonest UK Caucasian 20 mutations listed in Table 4. Our data confirms the proportion of $\Delta \mathrm{F} 508$ in the Caucasian population at $75.2 \%$, comparable to the Schwarz value of $75.3 \%$. There are similar frequencies for the more common mutations between our UK Caucasian CF data (Table 4) and the Schwarz data (respectively, G551D $3.43 \%$ and $3.08 \%$; G542X $1.84 \%$ and $1.68 \% ; 621+1 \mathrm{G} \rightarrow \mathrm{A}$ $1.27 \%$ and $0.93 \% ; 1717-1 \mathrm{G} \rightarrow \mathrm{A} 0.58 \%$ and $0.57 \%)$. In North America, $\Delta \mathrm{F} 508$ accounts for $71.2 \%$, with G542X (2.4\%), G551D (2.4\%), W1282X (1.4\%), N1303K (1.3\%) and R553X (0.9\%). ${ }^{8}$

Genotype frequencies in CF have previously been shown to fit a Hardy-Weinberg model in a smaller regional UK study. ${ }^{9}$ In the current study, we find that the genotype frequencies only satisfy the Hardy-Weinberg equilibrium provided we exclude those without an identified CFTR mutation in the Other/Other category. This suggests that defects in non-CFTR genes may contribute to the CF phenotype. Our pragmatic exclusion of all patients with untyped mutations in CFTR from the Other/Other group will of necessity exclude some patients with very rare mutations that are not picked up by routine genetic tests (20 kit, 31 kit etc). This might explain why the new observed values now fall below the expected values in the Other/Other category.

When compared with a European CFTR geographic distribution, ${ }^{10}$ the UK CF patients possess a greater proportion of $\Delta \mathrm{F} 508, \mathrm{G} 551 \mathrm{D}$ and $621+1 \mathrm{G} \rightarrow \mathrm{T}$ mutations, and a smaller proportion of G542X, N1303K, W1282X and R1162X mutations. In France, the five most common genotypes were $\Delta \mathrm{F} 508 / \Delta \mathrm{F} 508(47.8 \%), \Delta \mathrm{F} 508 / \mathrm{G} 542 \mathrm{X}(3.4 \%)$, $\Delta \mathrm{F} 508 / \mathrm{N} 1303 \mathrm{~K} \quad(2.7 \%), \Delta \mathrm{F} 508 / 1717-1 \mathrm{G} \rightarrow \mathrm{A} \quad(2.1 \%)$ and $\Delta \mathrm{F} 508 / 2789+5 \mathrm{G} \rightarrow \mathrm{A} \quad(1.5 \%) \quad$ (Desgeorges $\mathrm{M}$, personal communication) which is different to the commonest genotypes found in the UK population (Table 3). N1303K and G542X occur at a frequency of around 5\% in Italy. ${ }^{11}$ In Germany, a study of $658 \mathrm{CF}$ families revealed mutation frequencies of R553X (1.8\%), N1303K (1.3\%), G542X (1.1\%), G551D (0.8\%) and R347P (0.8\%). ${ }^{12}$ The frequency of CFTR mutations recorded for just over 1000 patients for the Irish CF Database include G551D in 7\%, R117H in $2 \%$ and $\Delta \mathrm{F} 508$ in $72 \%$ of patients. ${ }^{13}$ In the white South African population, a paper based on 192 patients found that $\Delta \mathrm{F} 508$ accounts for $76 \%$ of the mutations with 3272 $26 \mathrm{~A} \rightarrow \mathrm{G}(4 \%)$, 394delTT (3.6\%) and G542X (1.3\%) the other most common mutations. ${ }^{14}$ It is suggested that the 3272 $26 \mathrm{~A} \rightarrow \mathrm{G}$ and 394delTT mutations are more common due to a founder effect in white South Africans of European descent. Northern Ireland has a much greater proportion of Other/Other CF patients (where neither mutation is $\Delta \mathrm{F} 508)$ and although there is a higher incidence of CF in Northern Ireland (one in 1850), the population frequency of $\Delta \mathrm{F} 508$ is similar to other regions of the $\mathrm{UK}^{7}$

\section{CFTR mutations in the Non-Caucasian population}

Cystic Fibrosis is being increasingly diagnosed in the nonCaucasian populations, and the range of presenting features is similar between Caucasian and ISC groups (Table 1). The genotypes of non-Caucasian patients often contain individual or family specific mutations along with mutations more commonly found in Caucasians due to admixture of the populations. A recent paper by Malone et al, ${ }^{15}$ detected five novel CFTR mutations in 26 Pakistani patients and three of these mutations are reported in our 63 Pakistani patients. Malone's subgroup analysis of 14 Pakistani patients showed $32 \%$ of chromosomes had the $\Delta$ F508 mutation, similar to the $29 \%$ in our Pakistani patient data. In a small study of UK Asian CF patients, ${ }^{16}$ Bowler et al reported that these patients appeared to have a poorer respiratory and nutritional status compared to age matched controls, and noted that only $44 \%$ (four out of nine) patients had the $\Delta$ F508 mutation. In Spencer's study of ethnic minority children in the West Midlands ${ }^{17}, 31 \%$ (4/13) of patients from the ISC had the $\Delta \mathrm{F} 508$ mutation, but no other mutations were found. This study also found no overall delay in 
diagnosis between the white European CF patients and the CF patients from ethnic minorities. Our data confirms this finding that there is no delay in diagnosis between the Caucasian and non-Caucasian groups. $\Delta$ F508 carrier status has been estimated at one in 238 women from North India (Kapoor V, personal communication), giving an estimated frequency of the homozygote at one in 228000 . In a later study of 13 Indian CF children, Kapoor found the $\Delta \mathrm{F} 508$ mutation in $53.8 \%$ of chromosomes. ${ }^{18}$ Our study represents the largest reported group of UK CF patients from the ISC and finds that one in four has no CFTR mutation identified. The relative infrequency of the most common CFTR mutations in the ISC patients has implications for the national CF screening programme. Screening for the commonest mutations will detect smaller proportions of non-Caucasian CF individuals than their Caucasian counterparts. Our 27mutation virtual kit of mutations is particularly suited to detect mutations in the non-Caucasian as well as the Caucasian population, compared to the proposed 31-mutation kit or a combined kit of 38 mutations.

\section{Differences in presentation between UK and North America}

In common with CF populations studied in North America, Canada, Europe and Australasia, there is a male preponderance, ${ }^{19-21}$ and half of the patients remain in the paediatric age group. The over 30s represent only one in 10 patients. Comparison of the mode of presentation between the UK CF Database (Table 1) and the North American CF Patient Registry $^{8}$ reveals (respectively) differences in the rates of lower respiratory tract infection (34.6\% and 51.7\%), failure to thrive/malnutrition $(35.8 \%$ and $43.4 \%)$, steatorrhoea (29.0\% and $35.3 \%)$, meconium ileus (13.2\% and $20.8 \%$ ) and screening $(11.7 \%$ and $3.5 \%)$. It is noteworthy that the UK rate for presentation with meconium ileus $(13.2 \%)$ is very similar to the Canadian data $(13.4 \%) .^{21}$ In the UK, there were $63 \%$ patients diagnosed by 1 year of age (Table 2) compared to $70 \%$ in North America ${ }^{8}$ and $56.4 \%$ from the Canadian Patient Data Registry. ${ }^{22}$ In the UK CF Database, neonatal screening accounts for around one in 10 CF patients and the overall median age of diagnosis is 4 months, whilst in populations without screening, the mean age of CF diagnosis is reported at 5.7 months $^{23}$ and 11.7 months. ${ }^{5}$

\section{Summary}

The UK CF Database provides a framework for analysing the changing demographics of the CF population in the UK. The population is $96.4 \%$ Caucasian with a slight male preponderance. The commonest CFTR mutation, $\Delta \mathrm{F} 508$, is found in $74.1 \%$ of CF patients' chromosomes, and $\Delta \mathrm{F} 508$ homozygotes make up $57.5 \%$ of the Caucasian CF population. Detection of $96 \%$ of patients registered in the database is possible with the CFTR analysis proposed for the screening programme, but is unlikely to achieve the desired $>80 \%$ detection rates in the ethnic minority groups. The National Screening programme for CF must take account of the different range of CFTR mutations in the non-Caucasian CF population, so that screening also benefits patients from ethnic minorities.

\section{Acknowledgements}

The authors are grateful for the financial support of the CF Trust and the National Services Division of NHS (Scotland). We thank M Fraser and $K$ Nicol for their expert data validation, and in the large $C F$ Clinics, all the data entry staff and the Directors for their support. There are no conflicts of interest.

\section{References}

1 Riordan JR, Rommens JM, Kerem B et al: Identification of the cystic fibrosis gene: cloning and characterization of complementary DNA. Science 1989; 245: 1066-1073.

2 Farrell PM, Kosorok MR, Rock MJ et al: Early diagnosis of cystic fibrosis through neonatal screening prevents severe malnutrition and improves long-term growth. Pediatrics 2001; 107: 1-13.

3 Dodge JA, Morison S, Lewis PA et al: Incidence, population, and survival of cystic fibrosis in the UK, 1968-95. Arch Dis Child 1997; 77: $493-496$.

4 Merelle ME, Lees CM, Nagelkerke NF et al: Newborn Screening for Cystic Fibrosis (Cochrane Review) In the Cochrane Library 2000; 4. Oxford: Update Software.

5 Chatfield S, Owen G, Ryley HC et al: Neonatal Screening for cystic fibrosis in Wales and the West Midlands: clinical assessment after five years of screening. Arch Dis Child 1991; 66: 29-33.

6 Pollitt RJ, Dalton A, Evans S et al: Neonatal screening for cystic fibrosis in the Trent region (UK): two-stage immunoreactive trypsin screening compared with a three-stage protocol with DNA analysis as an intermediate step. J Med Screen 1997; 4: 23-28.

7 Schwarz MJ, Malone GM, Haworth A et al: Cystic Fibrosis Mutation Analysis: Report from 22 UK Regional Genetics Laboratories. Hum Mut 1995; 6: 326-333.

8 Cystic Fibrosis Patient Registry 2000 - Annual Data Report September 2001.

9 Green MR, Weaver LT, Heeley AF et al: Cystic fibrosis identified by neonatal screening: incidence, genotype, and early natural history. Arch Dis Child 1993; 68: 464-467.

10 Estivill X, Bancells C, Ramos C et al: Geographic distribution and regional origin of 272 cystic fibrosis mutations in European populations. Hum Mut 1997; 10: 135 - 154

11 Rendine S, Calafell F, Capello N et al: Genetic Distribution of cystic fibrosis mutations in Italy. 1 Regional distribution. Ann Hum Genet 1997; 61: 411-424.

12 Tummler B, Storrs T, Dziadek V et al: Geographic distribution and origin of CFTR mutations in Germany. Hum Genet 1996; 97: 727 731.

13 Cashman SM, Patino A, Delgado MG et al: The Irish Cystic Fibrosis Database. J Med Genet 1995; 32: 972-975.

14 Goldman A, Labrum R, Claustres $M$ et al: The molecular basis of cystic fibrosis in South Africa. Clin Genet 2001; 59: 37-41.

15 Malone G, Haworth A, Schwarz MJ, Cuppens H, Super M: Detection of five novel mutations of the cystic fibrosis transmembrane regulator (CFTR) gene in Pakistani patients with cystic fibrosis: Y569D, Q98X, 296+12(T > C), 1161delC and 621+2(T > C). Hum Mut 1998; 11: $152-157$.

16 Bowler IM, Estlin EJ, Littlewood JM: Cystic Fibrosis in Asians. Arch Dis Child 1993; 68: 120-122.

17 Spencer DA, Venkataraman M, Higgins S, Stevenson K, Weller PH: Cystic fibrosis in children from ethnic minorities in the West Midlands. Respir Med 1994; 88: 671-675. 
18 Kabra M, Ghosh M, Kabra SK, Khanna A, Verma IC: Delta F508 molecular mutation in Indian Children with cystic fibrosis. Indian J Med Res 1996; 104: 355-810.

19 Rosenfeld M, Davis R, Fitzsimmons S, Pepe M, Ramsey B: Gender gap in cystic fibrosis mortality. Am J Epidemiol 1997; 145: $794-$ 803.

20 Fogarty A, Hubbard R, Britton J: International Comparison of Median Age at Death from Cystic Fibrosis. Chest 2000; 117: $1656-1660$.
21 Kerem E, Corey M, Kerem B et al: Clinical and genetic comparisons of patients with cystic fibrosis, with or without meconium ileus. J Pediatr 1989; 114: 767-773.

22 Corey M, Farewell V: Determinants of mortality from cystic fibrosis in Canada, 1970 - 1989. Am J Epidemiol 1996; 143: 1007 - 1017.

23 Waters DL, Wilcken B, Irwig L et al: Clinical outcomes of newborn screening for cystic fibrosis. Arch Dis Child Fetal Neonatal Ed 1999; 80: F1-F7. 